CNS Spectrums (2014), 19, 197-205. (c) Cambridge University Press 2013. The online version of this article is published within an Open Access environment subject to the conditions of the Creative Commons Attribution-NonCommercial-ShareAlike licence <http://creativecommons.org/licenses/by-nc-sa/3.0/ > . The written permission of Cambridge University Press must be obtained for commercial re-use. doi:10.1017/S1092852913000904

\title{
Daytime sleepiness associated with lurasidone and quetiapine XR: results from a randomized double-blind, placebo-controlled trial in patients with schizophrenia
}

\author{
Antony D. Loebel, ${ }^{*}$ Cynthia O. Siu, ${ }^{2}$ Josephine B. Cucchiaro, 'Andrei A. Pikalov, \\ and Philip D. Harvey ${ }^{3}$
}

\footnotetext{
${ }^{1}$ Sunovion Pharmaceuticals Inc., Marlborough, Massachusetts, USA

${ }^{2}$ Data Power (DP) Inc., Flemington, New Jersey, USA

${ }^{3}$ University of Miami Miller School of Medicine, Miami, Florida, USA
}

Objective. The aim of this analysis was to compare the effects of 2 atypical antipsychotic agents, lurasidone $(80 \mathrm{mg} / \mathrm{d}$ or $160 \mathrm{mg} / \mathrm{d})$ and quetiapine XR $(600 \mathrm{mg} / \mathrm{d})$, on daytime alertness, and to evaluate the effects of daytime sleepiness on treatment outcomes in patients with an acute exacerbation of schizophrenia.

Methods. Patients who met Diagnostic and Statistical Manual of Mental Disorders, 4th edition, text revision (DSM-IVTR) criteria for schizophrenia were randomized to 6 weeks of double-blind treatment with fixed doses of lurasidone $80 \mathrm{mg} / \mathrm{d}(\mathrm{n}=125)$, lurasidone $160 \mathrm{mg} / \mathrm{d}(\mathrm{n}=121)$, quetiapine XR $600 \mathrm{mg} / \mathrm{d}(\mathrm{n}=119)$, or placebo $(\mathrm{n}=121)$, all dosed once daily in the evening, with food. Daytime sleepiness was assessed using the Epworth Sleepiness Scale (ESS).

Results. Daytime sleepiness improved in the lurasidone and placebo-treated groups but worsened in the quetiapine XR treatment group when compared to placebo $(p=0.001)$ and to either dose of lurasidone (both $p<0.01)$. Sedation associated with quetiapine XR treatment mediated an improvement in agitation [assessed by the Positive and Negative Syndrome Scale-Excitement (PANSS-EC) subscale] and a worsening in functional capacity [assessed by the University of California-San Diego (UCSD) Performance-Based Skills Assessment-Brief Version (UPSA-B) total score]; these mediating relationships were not observed for the lurasidone or placebo treatment groups.

Conclusion. In this 6-week double-blind study, treatment with lurasidone $80 \mathrm{mg}$ or $160 \mathrm{mg}$, administered once daily in the evening, was associated with a reduction in daytime sleepiness similar in magnitude to placebo, while quetiapine XR $600 \mathrm{mg} / \mathrm{d}$ was associated with a significant increase in daytime sleepiness, compared to both lurasidone dose groups and placebo. Daytime sleepiness was associated with improvement in agitation and worsening in functional capacity for quetiapine XR, but not lurasidone or placebo-treated patients.

Received 4 September 2013; Accepted 1 November 2013; First published online 13 December 2013

Key words: Atypical antipsychotics, daytime sleepiness, Epworth Sleepiness Scale, lurasidone, schizophrenia.

*Address for correspondence: Antony Loebel, MD, Sunovion Pharmaceuticals, Inc., One Bridge Plaza, Suite 510, Fort Lee, NJ 07024, USA.

(Email: antony.loebel@sunovion.com)

This work was supported by Sunovion Pharmaceuticals Inc.

Portions of this manuscript were previously presented at the New Clinical Drug Evaluation Unit (NCDEU) 52nd Annual Meeting,

Phoenix, Arizona, May 29-June 1, 2012.

ClinicalTrials.gov Identifier: NCT00790192.

\section{Introduction}

Daytime sleepiness (also known as daytime somnolence or sedation) associated with antipsychotic treatment may adversely impact functional performance and quality of life. ${ }^{1}$ Medications with significant antihistaminergic effects, such as diphenhydramine and certain antipsychotic agents, are commonly associated with daytime sleepiness. Previous studies have suggested that daytime sleepiness can impair 
cognition, including concentration and alertness, and may interfere with daily work and task performance. ${ }^{1-3}$ In addition, daytime sleepiness may impair driving skills and increase risk for accidents. The American Academy of Sleep Medicine (AASM) estimated that on average, 80,000 U.S. drivers fall asleep while driving every day, and up to $20 \%$ of all serious car crash injuries are associated with driver sleepiness, independent of the other major factor of driving under the influence of alcohol. ${ }^{3}$ The adverse impact of daytime sleepiness on personal health, performance, and well-being is therefore substantial, and translates into significant economic loss for both individuals and society. ${ }^{1-4}$

Despite awareness of the significant health and economic burden posed by daytime sleepiness in the general population, ${ }^{4}$ and the propensity for antipsychotic agents to induce sedation, the effects of daytime sleepiness on patient outcomes in schizophrenia have not been adequately studied. In particular, few schizophrenia trials have included a systematic or objective assessment of daytime somnolence associated with drug treatment. ${ }^{5-8}$ The objective of this analysis was to evaluate the effects of 2 atypical antipsychotic agents, lurasidone and quetiapine $\mathrm{XR}$, on daytime alertness, and the mediating effects of daytime sleepiness on clinical, cognitive, and functional outcomes in patients with an acute exacerbation of schizophrenia.

\section{Materials and Methods}

\section{Design}

This was a randomized, double-blind, placebo- and activecontrolled study in which subjects with a primary diagnosis of schizophrenia who were recently hospitalized for an acute exacerbation of psychotic symptoms were randomly assigned to 6 weeks of double-blind treatment with oncedaily, evening doses of lurasidone (80 mg or $160 \mathrm{mg}$ ), quetiapine XR $(600 \mathrm{mg}$, included to establish assay sensitivity), or placebo. Study methods have been described in detail elsewhere ${ }^{9}$ and are summarized here. This multinational study was conducted between October 21, 2008, and June 2, 2010, and randomized a total of 488 subjects at 24 centers in the United States $(n=151$ subjects) and 39 centers in the following countries: Russia $(\mathrm{n}=87)$, India $(\mathrm{n}=98)$, Ukraine $(\mathrm{n}=75)$, Romania $(\mathrm{n}=49)$, and Colombia $(\mathrm{n}=26) .{ }^{9}$ The study was conducted in accordance with the International Conference on Harmonization Good Clinical Practices guidelines and with the ethical principles of the Declaration of Helsinki. An independent data and safety monitoring board reviewed safety data at regular intervals during the study.

\section{Subjects}

Hospitalized male and female subjects between the ages of 18 and 75 years who met Diagnostic and Statistical
Manual of Mental Disorders, 4th edition, text revision (DSM-IV-TR) criteria for a primary diagnosis of schizophrenia, which was confirmed by the Mini International Neuropsychiatric Interview-Plus (MINI-Plus), ${ }^{10}$ were enrolled. Subjects were required to have an illness duration greater than 1 year; the current acute exacerbation of psychotic symptoms was to be no longer than 2 months. At the screening and baseline visits, subjects were required to have a Clinical Global ImpressionSeverity (CGI-S) score $\geq 4$ (moderately severe or greater) and a Positive and Negative Syndrome Scale (PANSS) total score $\geq 80$, including a score $\geq 4$ (moderately severe or greater) on 2 or more of the following PANSS items: delusions, conceptual disorganization, hallucinations, unusual thought content, and suspiciousness.

\section{Study medication}

All study medication was identically over-encapsulated to preserve the double-blind nature of the study. Subjects were evaluated for eligibility during a screening period of up to 14 days, during which all psychotropic medications were tapered off in a manner consistent with labeling recommendations and conventional medical practice. Subjects then completed a 3- to 7-day placebo washout period. At baseline (Day 0), subjects who continued to meet all study entry criteria were randomly assigned via an interactive voice response system (in a 1:1:1:1 ratio) to 1 of 4 treatment arms: lurasidone $80 \mathrm{mg} / \mathrm{d} \quad(\mathrm{N}=125)$, lurasidone $160 \mathrm{mg} / \mathrm{d}$ $(\mathrm{N}=121)$, quetiapine $\mathrm{XR} \quad 600 \mathrm{mg} / \mathrm{d} \quad(\mathrm{N}=119)$, or placebo $(\mathrm{N}=121)$. Study medication was administered once daily in the evening with a meal or within 30 minutes after eating. Subjects assigned to lurasidone $80 \mathrm{mg} / \mathrm{d}$ started treatment at their target dose. Subjects assigned to lurasidone $160 \mathrm{mg} / \mathrm{d}$ started treatment at a dose of $120 \mathrm{mg} / \mathrm{d}$ for 2 days and were then increased to their target dose. Subjects assigned to quetiapine XR $600 \mathrm{mg} / \mathrm{d}$ were started at a dose of $300 \mathrm{mg} / \mathrm{d}$ for 2 days and were then increased to their target dose. The quetiapine XR dose of $600 \mathrm{mg} / \mathrm{d}$ was selected for use in this study because it is at the mid-point of the therapeutic dose range $(400-800 \mathrm{mg} / \mathrm{d})$ for this agent, and has been shown to be effective and generally well-tolerated in the treatment of patients with acute schizophrenia. ${ }^{11,12}$ Subjects were eligible for hospital discharge after completing a minimum of 21 days of double-blind treatment if specific clinical stability criteria were met.

\section{Assessments}

Daytime sleepiness was assessed using the Epworth Sleepiness Scale (ESS) at the baseline, week 3, and week 6 visits. The ESS is a patient-reported questionnaire, which consists of 8 items that describe various routine 
daily life situations. ${ }^{6,7}$ Subjects rate the likelihood of dozing or falling asleep (distinguishing dozing behavior from feelings of tiredness) in each of these situations, on a 4-point scale from 0 to 3 ; items are summed to produce a total score (range of 0-24). The ESS has been shown to be reliable and valid, in that it correlates reasonably well with laboratory measures of sleepiness $[\mathrm{eg} \text {, the multiple sleep latency test (MSLT) }]^{13}$ and has been shown to be sensitive to treatment-related improvement in sleep disorder populations. It has been validated in both case-control studies of normal subjects and several patient populations with different types of sleep disorders. ${ }^{6,7}$ In addition, the ESS has been utilized for the assessment of daytime sleepiness in patients with schizophrenia. ${ }^{8,14}$ Scores higher than 10 are considered to indicate significant, i.e., markedly high, daytime sleepiness. ${ }^{7}$ If one or more Epworth Sleepiness Scale items were missing at a visit, the total score would be set to missing. Primary efficacy outcomes were assessed using the PANSS total and subscale scores, ${ }^{15}$ and have been published in full elsewhere. ${ }^{9}$ Agitation was assessed using the PANSS Excitement subscale (PANSS-EC). ${ }^{16}$ Cognitive performance was assessed at baseline and week 6 with the CogState Computerized Schizophrenia Battery, ${ }^{17}$ using a composite $\mathrm{Z}$ score. Functional capacity was assessed using the University of California-San Diego (UCSD) Performance-Based Skills Assessment-Brief Version (UPSA-B) at baseline and week $6{ }^{18}$ The UPSA-B total score ranges from 0 to 100 points, with higher scores reflecting better performance.

\section{Statistical methods}

A mediation regression approach ${ }^{19,20}$ was applied to explore the potential effect of daytime sleepiness (mediator) and its association with study antipsychotic treatments (exogenous causal variable) on changes in the PANSS-EC, cognitive, and functional capacity. The parameters of the mediation regression models were estimated separately for each of these outcome measures. The effects of ESS change scores on mediating changes in the outcome measures (agitation, cognitive, and functional performance) were estimated by a series of analysis of covariance (ANCOVA) models, which included terms for baseline score, center, terms for main and interaction effects of ESS change scores, and treatment groups. The direct effect of treatment on change in ESS total scores (mediator) was estimated by ANCOVA, which included terms for baseline, center, and treatment. Because cognitive and UPSA-B assessments could be affected by cultural differences, analyses were performed for subjects in all sites as well as the subgroup recruited from U.S. sites. ${ }^{21}$

\section{Results}

Baseline demographic and clinical characteristics were comparable among the 4 treatment groups (Table 1). Change in the ESS total score at week 6 (last observation carried forward; LOCF) was not significantly different for the lurasidone $80 \mathrm{mg} / \mathrm{d}(-1.1$,

TABLE 1. Baseline characteristics of patients with schizophrenia in a 6-week randomized, double-blind, placebo-, and quetiapine XR-controlled study of lurasidone (safety population)

\begin{tabular}{|c|c|c|c|c|}
\hline & Lurasidone $160 \mathrm{mg} / \mathrm{d}$ & Lurasidone $80 \mathrm{mg} / \mathrm{d}$ & Quetiapine XR $600 \mathrm{mg} / \mathrm{d}$ & Placebo \\
\hline & $\mathrm{N}=121$ & $\mathrm{~N}=125$ & $\mathrm{~N}=119$ & $N=121$ \\
\hline Age, mean (SD) & $37.9(11.3)$ & $36.2(10.9)$ & $37.4(10.4)$ & $37.4(10.8)$ \\
\hline Minimum, maximum & $18-63$ & $18-61$ & $18-58$ & $19-65$ \\
\hline \multicolumn{5}{|l|}{ Gender, n (\%) } \\
\hline Male & $82(68 \%)$ & $96(77 \%)$ & $77(65 \%)$ & $77(64 \%)$ \\
\hline Female & $39(32 \%)$ & $29(23 \%)$ & $42(35 \%)$ & $44(36 \%)$ \\
\hline \multicolumn{5}{|l|}{ Race, n (\%) } \\
\hline White & $63(52 \%)$ & $75(60 \%)$ & $69(58 \%)$ & $68(56 \%)$ \\
\hline Black & $29(24 \%)$ & $22(18 \%)$ & $19(16 \%)$ & $25(21 \%)$ \\
\hline Asian/other & $29(24 \%)$ & $28(22 \%)$ & $31(26 \%)$ & $28(23 \%)$ \\
\hline \multicolumn{5}{|l|}{ PANSS total score ${ }^{*}$} \\
\hline Mean (SD) & $97.5(11.8)$ & $97.7(-9.7)$ & $97.7(-10.2)$ & $96.6(10.2)$ \\
\hline \multicolumn{5}{|l|}{ PANSS Positive Subscale ${ }^{\ddagger}$} \\
\hline Mean (SD) & $25.8(3.7)$ & $26.1(3.7)$ & $26.1(3.5)$ & $25.2(3.6)$ \\
\hline \multicolumn{5}{|l|}{ PANSS Negative Subscale ${ }^{*}$} \\
\hline Mean (SD) & $24.2(4.6)$ & $24.2(3.8)$ & $24.0(3.6)$ & $24.3(4.2)$ \\
\hline \multicolumn{5}{|l|}{ PANSS Excitement Subscale ${ }^{*}$} \\
\hline Mean (SD) & $14.4(3.6)$ & $14.2(3.4)$ & $14.5(3.5)$ & $13.9(3.8)$ \\
\hline \multicolumn{5}{|l|}{ Epworth Sleepiness Scale Total ${ }^{\ddagger}$} \\
\hline Mean (SD) & $6.0(4.7)$ & $6.0(4.8)$ & $6.0(4.1)$ & $6.2(4.6)$ \\
\hline
\end{tabular}

${ }^{\ddagger}$ Data for these parameters are based on the intent-to-treat population. 


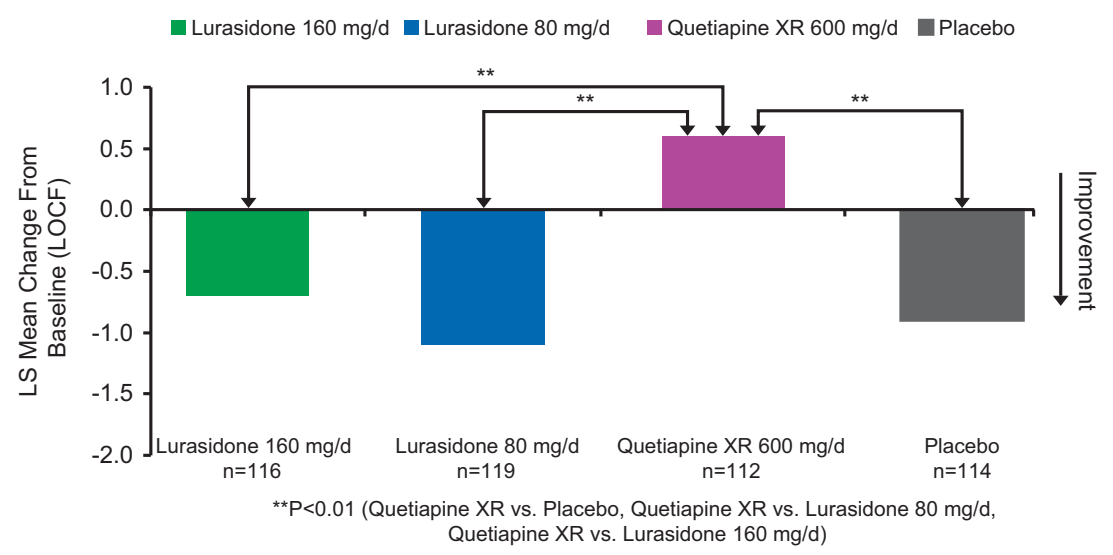

FIGURE 1. Change from baseline in Epworth Sleepiness Scale.

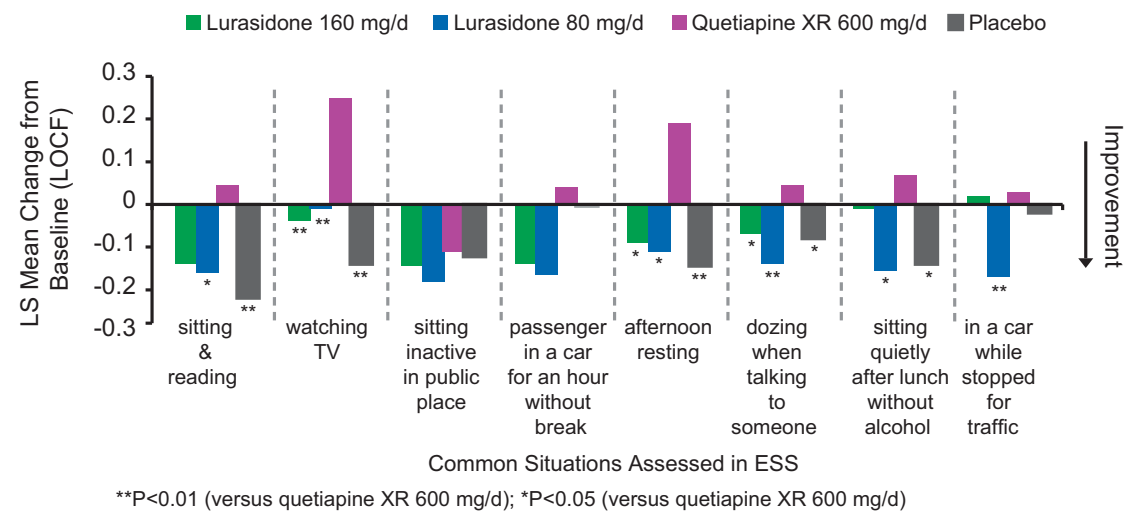

FIGURE 2. Change from baseline in Epworth Sleepiness Scale: Item analysis.

SE 0.3) and $160 \mathrm{mg} / \mathrm{d}$ groups (-0.7, SE 0.3) compared with the placebo group (-0.9, SE 0.3). The quetiapine XR $600 \mathrm{mg} / \mathrm{d}$ group $(+0.6$, SE 0.3$)$ was associated with a significant increase in the ESS total score compared to placebo $(-0.9$, SE $0.3, p=0.001)$ and to lurasidone ( $p<0.001$ for lurasidone $80 \mathrm{mg} ; \mathrm{p}<0.01$ for lurasidone $160 \mathrm{mg}$ ) (see Figure 1). The proportion of subjects who experienced markedly high sleepiness was significantly greater in the quetiapine XR group compared to the lurasidone $80 \mathrm{mg} / \mathrm{d}$ group [ $\mathrm{p}=0.021$; number needed to treat/harm $(\mathrm{NNTH})=12$ ], and was numerically higher compared to the lurasidone $160 \mathrm{mg} / \mathrm{d}$ group $(\mathrm{p}=0.081 ; \mathrm{NNTH}=15)$.

Change in each of the 8 ESS items at week 6 (LOCF) was not significantly different between either of the lurasidone groups and the placebo group (all $\mathrm{p}>0.05$ ). Change from baseline in 5 of the 8 ESS items was significantly greater (reflecting increased sedation) in the quetiapine XR group when compared with the placebo group (see Figure 2). The quetiapine XR group was also associated with a significant increase in sedation in 6 of the 8 ESS items compared with either the lurasidone $80 \mathrm{mg}$ or $160 \mathrm{mg}$ group (Figure 2).

\section{Drug induced sedation: effect on agitation}

Improvement in the PANSS-EC subscale score at week 6 was significantly greater for the lurasidone (both $\mathrm{p}<0.001)$ and quetiapine XR $(\mathrm{p}<0.001)$ groups compared to the placebo group (Figure 3). Increase in the ESS total score (increase in sedation) in the quetiapine XR group (versus placebo group) was associated with improvement in agitation, as assessed by the PANSS-EC subscale $(p=0.042)$, and interaction effect of change in ESS and quetiapine XR versus placebo, but not for either dose of lurasidone $[p=0.258$, interaction effect of change in ESS and pooled lurasidone dose groups (versus placebo)]. Increase in the ESS total score was not significantly associated with improvement in PANSS total and subscales (positive and negative symptoms) scores in either lurasidone group nor the quetiapine XR group versus placebo (all $\mathrm{p}>0.05$ ). 


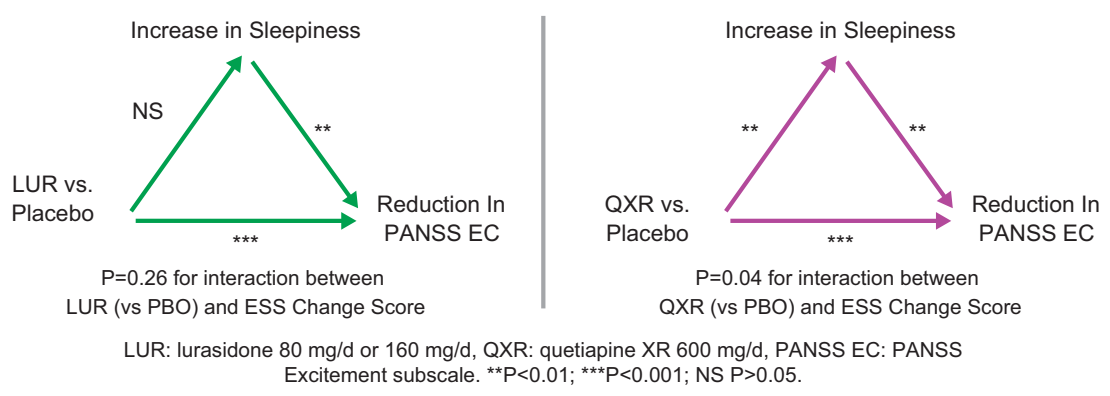

FIGURE 3. Change in sleepiness as a mediator of change in PANSS excitement subscale: Mediation regression analysis.

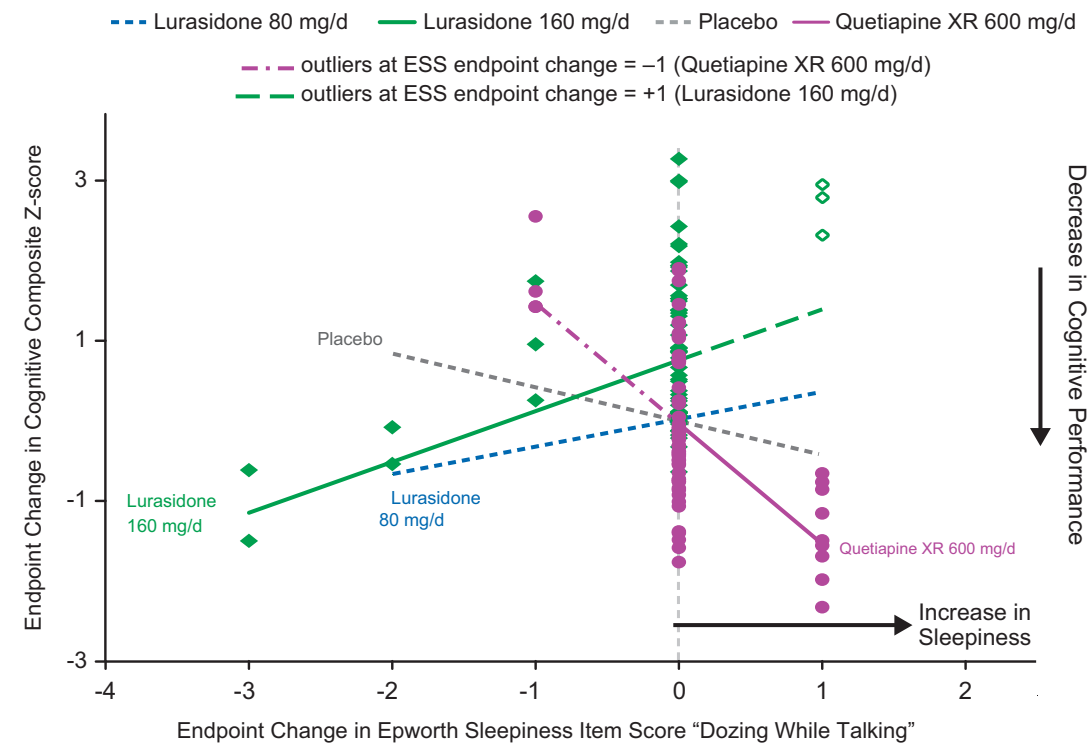

$P=0.015$ for interaction between quetiapine XR $600 \mathrm{mg} / \mathrm{d}$ (vs. lurasidone $160 \mathrm{mg} / \mathrm{d}$ ) and ESS change score.

FIGURE 4. Change in sleepiness ESS item 'dozing while talking' and change composite Z score: Mediation regression analysis.

\section{Drug induced sedation: effect on cognitive and functional performancel}

In patients whose neurocognitive testing results were evaluable (based on prespecified criteria for the validity of the cognitive tests, $n=267$ ), the effect of lurasidone $160 \mathrm{mg} / \mathrm{d}$ on cognitive performance (LS mean change 0.5 , SE 0.24$)$ was superior to both placebo $(-0.16$, SE $0.23, \mathrm{p}=0.038)$ and quetiapine XR $(-0.24$, SE 0.23 , $\mathrm{p}=0.018$ ), as assessed by the CogState composite Zscore. ${ }^{22}$ We assessed the potential mediating relationship between each of the 8 ESS items and the effect on the CogState composite score, for all treatment groups. Notably, increase in the ESS item 6 score ("dozing when talking") was associated with a worsening of overall cognitive performance in the quetiapine XR group, showing a significant difference in mediating relationship (slope) compared to the lurasidone $160 \mathrm{mg} / \mathrm{d}$ group $(\mathrm{p}=0.006$, U.S. sites; and $\mathrm{p}=0.015$, all subjects, but not with placebo or lurasidone $80 \mathrm{mg} / \mathrm{d}$ groups) (Figure 4). There were no consistently significant associations between changes in other ESS items and cognitive performance at week 6 for lurasidone or quetiapine XR (all subjects or U.S. sites).

Among subjects recruited from U.S. sites, increase in the ESS total score (reflecting increased sedation) during quetiapine XR treatment was associated with a worsening in the UPSA-B total score $(p=0.003$ for the difference in slopes between quetiapine and placebo, U.S. subjects only) (Figure 5); this relationship was not seen for the lurasidone treatment groups and was not observed in non-U.S., nor all subjects combined $(\mathrm{p}>0.05)$.

\section{Adverse events}

The most commonly reported adverse events in each active treatment group (incidence at least $5 \%$ and at 


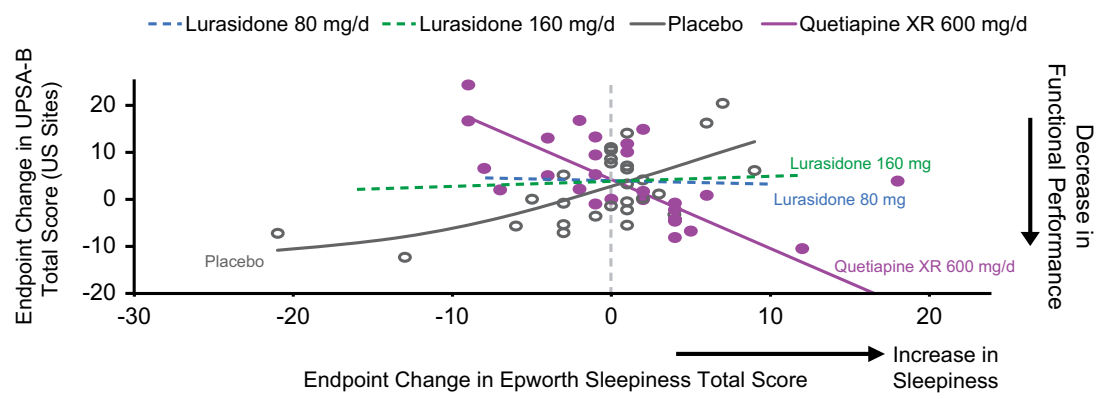

$P=0.003$ for interaction between quetiapine $X R 600 \mathrm{mg} / \mathrm{d}$ (versus placebo) and ESS change Score.

FIGURE 5. Change in sleepiness and change in UPSA-B performance score: mediation regression analysis.

TABLE 2. Most commonly reported adverse events (incidence $\geq 5 \%$ and $\geq 2$ placebo rate in each active treatment group) during 6 weeks of treatment with lurasidone, quetiapine XR, or placebo (safety population)

\begin{tabular}{|c|c|c|c|c|}
\hline & Lurasidone $160 \mathrm{mg} / \mathrm{d}$ & Lurasidone $80 \mathrm{mg} / \mathrm{d}$ & Quetiapine XR $600 \mathrm{mg} / \mathrm{d}$ & Placebo \\
\hline & $\mathrm{N}=121$ & $\mathrm{~N}=125$ & $\mathrm{~N}=119$ & $\mathrm{~N}=121$ \\
\hline & $\%$ & $\%$ & $\%$ & $\%$ \\
\hline Akathisia & 7.4 & 8.0 & 1.7 & 0.8 \\
\hline Parkinsonism & 6.6 & 5.6 & 3.4 & 0 \\
\hline Nausea & 6.6 & 8.0 & 3.4 & 3.3 \\
\hline Dizziness & 5.8 & 4.8 & 13.4 & 1.7 \\
\hline Somnolence & 6.6 & 4.0 & 13.4 & 0.8 \\
\hline Constipation & 0.8 & 2.4 & 6.7 & 2.5 \\
\hline Dry mouth & 1.7 & 1.6 & 7.6 & 0.8 \\
\hline Arthralgia & 0.8 & 1.6 & 5.9 & 0.8 \\
\hline Upper respiratory infection & 0.8 & 1.6 & 5.0 & 0.8 \\
\hline Weight increased & 1.7 & 0.8 & 6.7 & 0.8 \\
\hline
\end{tabular}

least twice the placebo rate; see Table 2) were akathisia, parkinsonism, and nausea for the lurasidone $80 \mathrm{mg} / \mathrm{d}$ group; akathisia, parkinsonism, somnolence, nausea, and dizziness for the lurasidone $160 \mathrm{mg} / \mathrm{d}$ group; and dizziness, somnolence, dry mouth, constipation, weight increased, arthralgia, and upper respiratory tract infection for the quetiapine XR $600 \mathrm{mg} / \mathrm{d}$ group.

\section{Discussion}

This is the first placebo-controlled study in patients with acute schizophrenia to compare the effects of antipsychotic agents (lurasidone and quetiapine XR) on daytime sleepiness, using a validated self-report instrument, the Epworth Sleepiness Scale. ${ }^{6,7}$ The proportion of patients experiencing somnolence or sedation in clinical trials is most commonly assessed based only on the spontaneously reported frequency of these adverse events. ${ }^{1}$ This approach may be limited by the ability and willingness of investigators to elicit and patients to report such adverse effects. In addition, we evaluated the effects of daytime sleepiness on key measures of treatment outcome, including severity of agitation, cognition, and functional capacity.

Change in the ESS total score was similar for lurasidone (at fixed daily doses of $80 \mathrm{mg}$ and $160 \mathrm{mg}$ ) and placebo over 6 weeks in this study, with both groups showing a reduction in sleepiness from study baseline. Quetiapine $\mathrm{XR}$ (at a fixed daily dose of $600 \mathrm{mg}$ ) was associated with a significant mean increase in daytime sleepiness when compared to placebo or either dose of lurasidone. This effect persisted over the course of the study (6 weeks), which suggests that this adverse effect did not habituate over time. Markedly high daytime sleepiness (ESS total score $>10$ ) occurred significantly more often in the quetiapine XR group (19\%) compared to placebo (13\%) or either dose of lurasidone (10-12\%). These findings indicate that high levels of daytime somnolence occur in association with lurasidone and placebo at comparable rates, but are observed more frequently in association with quetiapine XR treatment. These results are consistent with differences in the rates of treatment-emergent somnolence reported as an adverse event in this study (lurasidone, $5.3 \%$; quetiapine XR, $13.4 \%$; and placebo, $0.8 \%) .{ }^{10}$ 
We note that several prior studies have specifically examined sedating effects of quetiapine in patient populations. In a previous 1-day, crossover study of clinically stable patients with bipolar disorder, a single dose of quetiapine led to significant decrements in cognitive test performance and increased somnolence and daytime sleepiness compared to risperidone treatment. ${ }^{5}$ Both quetiapine extended-release and quetiapine immediate-release have been shown to produce similar high levels of sedation intensity 4-14 hours postdose in a randomized, double-blind study involving inpatients with bipolar depression. ${ }^{23}$ The increased rates of sedation observed in quetiapine XR-treated patients in the current study are consistent with these observations.

Our findings that lurasidone is associated with lower levels of daytime sleepiness than quetiapine may be expected, based in part on the differential receptor pharmacology of these agents. Specifically, quetiapine is associated with high affinity at the $\mathrm{H}_{1}$ receptor where it acts as an antagonist ${ }^{11}$; this mechanism is associated with sedation in both animal models and human studies. ${ }^{24}$ In contrast, lurasidone has no affinity at the $\mathrm{H}_{1}$ receptor subtype, ${ }^{25}$ and has not been associated with impairments in cognition or high levels of sedation in prior studies. The relative propensity to induce sedation among multiple antipsychotic agents has been examined by Leucht et $\mathrm{al}^{26}$ in a multiple-treatments meta-analysis. Lurasidone was ranked as 6 and quetiapine as 11 out of 15 antipsychotic agents (higher number indicates greater sedation). ${ }^{26}$

In this 6-week study, both lurasidone $80 \mathrm{mg} / \mathrm{d}$ and $160 \mathrm{mg} / \mathrm{d}$ dose groups, as well as quetiapine XR $600 \mathrm{mg} / \mathrm{d}$, were associated with comparable and significant reductions in agitation, as assessed using the PANSS-EC subscale. However, using mediator regression modeling, daytime sleepiness associated with quetiapine XR treatment was found to be a mediator of change in agitation for quetiapine $\mathrm{XR}$, but not for either dose of lurasidone. These results suggest that reduction in agitation may be accounted for, in part, by induction of sleepiness in patients treated with quetiapine $\mathrm{XR}$, but not lurasidone.

An analysis of evaluable neurocognitive testing scores in the current study (using the CogState computerized cognitive battery) found that lurasidone $160 \mathrm{mg} / \mathrm{d}$ was superior to both placebo and quetiapine $\mathrm{XR}$ in cognitive performance at week $6 .^{22}$ While the mechanistic basis for these observed improvements in cognition is not well understood, it is possible that the serotonin 5HT-7 receptor subtype (where lurasidone binds with high affinity and acts as an antagonist) plays a significant role in mediating these effects. ${ }^{27}$ The change in the ESS total score associated with both lurasidone $80 \mathrm{mg} / \mathrm{d}$ and $160 \mathrm{mg} / \mathrm{d}$ dose groups, and quetiapine XR $600 \mathrm{mg} / \mathrm{d}$, was not a significant mediator of change in the cognitive composite performance score. However, analysis of the
ESS item scores showed that an increase in the ESS item score 6 ("propensity to doze when talking to someone") was found to be associated with a worsening of cognitive performance in the quetiapine XR group compared to the lurasidone $160 \mathrm{mg} / \mathrm{d}$ group. These results suggest that cognitive performance may be adversely affected by specific types of soporific effects, as characterized by selected ESS items. This finding is consistent with the psychometric basis for the ESS, where items were intended to assess the level of sleepiness in situations known to vary in their soporific qualities. ${ }^{6,7}$ We note that the ESS composite score, which incorporates subjects' impression of the likelihood to doze off or fall asleep while engaging in mostly passive activities, may not be a sufficiently sensitive correlate to cognitive performance. Among the 8 different situations, the ESS item "dozing while talking" is the only activity that involves the kind of attention, alertness, and active engagement required in social interactions. These results suggest that sleepiness experienced in specific situations, particularly sleepiness related to higher-level cognitive or social interactive tasks, may exert more influence on cognitive performance than other forms of somnolence.

Both the lurasidone $80 \mathrm{mg} / \mathrm{d}$ and $160 \mathrm{mg} / \mathrm{d}$ dose groups as well as the quetiapine XR $600 \mathrm{mg} / \mathrm{d}$ group were associated with comparable and significant improvement in functional capacity, as assessed using the UPSAB. Daytime sleepiness associated with quetiapine XR treatment was found to be a mediator of change in functional capacity for quetiapine XR among subjects from U.S. sites, but not for either dose of lurasidone (Figure 4). Notably, this relationship was not observed in non-U.S. subjects (or in the full study sample). It is possible that cultural differences make the UPSA-B less sensitive to change in functional capacity in non-U.S. regions. ${ }^{21}$ Our findings from the U.S. sites suggest that quetiapine XR-associated daytime sleepiness may lead to impaired functional performance; this relationship between daytime sedation and functional capacity change was not observed for lurasidone or placebo, perhaps due to the lack of soporific effects induced by these treatments.

Some limitations of these findings should be noted. The fixed-dose design of the placebo-controlled trial from which these data were derived did not permit investigators an opportunity to individualize treatment and therefore optimize tolerability for each agent, including with regard to the level of daytime sleepiness or sedation. Although several studies have reported that ESS total scores correlated significantly with laboratory measures of mean sleep latency, such as the MSLT, in patients with various sleep disorders, ${ }^{6,7}$ others have reported lower correlations. $^{28}$ Since patients with schizophrenia may have reduced insight, this could 
have reduced the accuracy of patient report regarding perceived levels of daytime sleepiness; however the differences observed among the treatment groups in this study suggest that the ESS is sensitive to change in this patient population. The regression model used for analyzing the mediating effect of daytime sleepiness on various treatment outcomes involved a statistical interaction term for treatment and change in the ESS total score. It is possible that the absence of a mediating effect for some ESS items may have been due to a lack of statistical power and limited range of the variables. Further studies are warranted to verify these exploratory analysis findings utilizing other antipsychotic agents to determine the generalizability of these results. The effect of lurasidone and quetiapine $\mathrm{XR}$ on measures of daytime sleepiness in longer-term treatment will be reported elsewhere.

\section{Conclusions}

Our findings underscore the observation that secondgeneration, atypical antipsychotic agents have distinct efficacy and adverse effect profiles, and hence are not easily interchangeable. ${ }^{29,30}$ In this study, treatment with fixed-dose lurasidone $80 \mathrm{mg}$ or $160 \mathrm{mg}$, administered for 6 weeks once daily in the evening, was associated with a reduction in daytime sleepiness, of similar magnitude to placebo, while treatment with quetiapine XR $600 \mathrm{mg}$ was associated with a significant increase in selfreported daytime sleepiness compared to placebo. Our findings suggest that daytime somnolence may have a significant impact on cognitive and functional outcomes. In addition, these findings support the use of the ESS as a brief and practical tool for the assessment of daytime sleepiness in patients with schizophrenia and provide evidence for its sensitivity to change during treatment with antipsychotic agents.

\section{Disclosures}

This work was supported by Sunovion Pharmaceuticals Inc.

Dr. Siu has received payment for consulting from Pfizer Inc., Sunovion Pharmaceuticals Inc., and the Center for Addiction and Mental Health at the University of Toronto. Dr. Harvey serves as a consultant/advisory board member for Abbvie, Boeheringer Ingelheim, Bristol-Myers-Squibb, Forest Labs, Genentech, Roche, Shire, Sunovion, and Takeda. Drs. Cucchiaro, Loebel, and Pikalov are employees of Sunovion Pharmaceuticals Inc.

\section{REFERENCES:}

1. Kane JM, Sharif ZA. Atypical antipsychotics: sedation versus efficacy. J Clin Psychiatry. 2008; 69(Suppl 1): 18-31.

2. Hawley CJ, Gale TM, Sivakumaran T, et al. Excessive daytime sleepiness in psychiatric disorders: prevalence, correlates and clinical significance. Psychiatry Res. 2010; 175(1-2): 138-141.

3. American Academy of Sleep Medicine (AASM). Driving Fact Sheet, December 2, 2009. http://www.aasmnet.org/Resources/ Factsheets/DrowsyDriving.pdf. Accessed July 26, 2012.

4. Colten HR, Altevogt BM, eds. Sleep Disorders and Sleep Deprivation: An Unmet Public Health Problem. Washington, DC: National Academy of Sciences. http://www.ncbi.nlm.nih.gov/ books/NBK19958. Accessed July 16, 2012.

5. Harvey PD, Hassman H, Mao L, et al. Cognitive functioning and acute sedative effects of risperidone and quetiapine in patients with stable bipolar 1 disorder: a randomized, double-blind, crossover study. J Clin Psychiatry. 2007; 68(8): 1186-1194.

6. Johns MA. A new method for measuring daytime sleepiness: the Epworth Sleepiness Scale. Sleep. 1991; 14(6): 540-545.

7. Johns MW. Epworth Sleepiness Scale (ESS). In Rush Jr AJ, First MB, Blacker D, Eds. Handbook of Psychiatric Measures, 2nd ed.Washington, DC: American Psychiatric Publishing; 2008.

8. Fleischhacker WW, Heikkinen ME, Olié JP, et al. Effects of adjunctive treatment with aripiprazole on body weight and clinical efficacy in schizophrenia patients treated with clozapine: a randomized, double-blind, placebo-controlled trial. Int J Neuropsychopharmacol. 2010; 13(8): 1115-1125.

9. Loebel A, Cucchiaro J, Sarma K, et al. Efficacy and safety of lurasidone $80 \mathrm{mg} /$ day and $160 \mathrm{mg} /$ day in the treatment of schizophrenia: a randomized, double-blind, placebo- and activecontrolled trial. Schizophrenia Res. 2013; 145(1-3): 101-109.

10. Sheehan DV, Lecrubier Y, Sheehan KH, et al. The MiniInternational Neuropsychiatric Interview (M.I.N.I.): the development and validation of a structural diagnostic psychiatric interview for DSM-IV and ICD-10 1996. J Clin Psychiatry. 1998; 59(Suppl 20): 22-23.

11. Baldwin CM, Scott LJ. Quetiapine extended release: in schizophrenia. CNS Drugs. 2009; 23(3): 261-269.

12. Zhornitsky S, Potkin S, Moteshafi H, et al. Dose-response and comparative efficacy and tolerability of quetiapine across psychiatric disorders: a systematic review of the placebo-controlled monotherapy and add-on trials. Int Clin Psychopharmacol. 2011; 26(4): 183-189.

13. Chervin RD. The multiple sleep latency test and Epworth Sleepiness Scale in the assessment of daytime sleepiness. J Sleep Res. 2000; 9(4): 397-400.

14. Lohr JB, Liu L, Caligiuri MP, et al. Modafinil improves antipsychotic-induced parkinsonism but not excessive daytime sleepiness, psychiatric symptoms or cognition in schizophrenia and schizoaffective disorder: a randomized, double-blind, placebocontrolled study. Schizophr Res. 2013; 150: 289-296.

15. Kay SR, Fiszbein A, Opler LA. The Positive and Negative Syndrome Scale (PANSS) for schizophrenia. Schizophr Bull. 1987; 13(2): 261-276.

16. Lindenmayer JP, Brown E, Baker RW, et al. An excitement subscale of the Positive and Negative Syndrome Scale. Schizophrenia Res. 2004; 68(2-3): 331-337.

17. Pietrzak RH, Olver J, Norman T, et al. A comparison of the CogState schizophrenia battery and the Measurement and Treatment Research to Improve Cognition in Schizophrenia (MATRICS) battery in assessing cognitive impairment in chronic schizophrenia. J Clin Exp Neuropsychol. 2009; 31(7): 848-859.

18. Mausbach BT, Harvey PD, Goldman SR, et al. Development of a brief scale of everyday functioning in persons with serious mental illness. Schizophr Bull. 2007; 33(6): 1364-1372.

19. Mackinnon DP, Fairchild AJ, Matthew SF. Mediation analysis. Annu Rev Psychol. 2007; 58: 593-614.

20. Kraemer HC, Wilson GT, Fairburn CG, et al. Mediators and moderators of treatment effects in randomized clinical trials. Arch Gen Psychiatry. 2002; 59(10): 877-883. 
21. Harvey PD, Velligan DI. International assessment of functional skills in people with schizophrenia: innovations in clinical neuroscience. Innov Clin Neurosci. 2011; 8(1): 15-18.

22. Harvey PD, Siu CO, Hsu J, et al. Effect of lurasidone on neurocognitive performance in patients with schizophrenia: a short-term placebo- and active-controlled study followed by a 6-month double-blind extension. Eur Neuropsychopharmacol. 2013; 23(11): 1373-1382.

23. Riesenberg RA, Baldytcheva I, Datto C. Self-reported sedation profile of quetiapine extended-release and quetiapine immediatereleased during 6-day initial dose escalation in bipolar depression: a multicenter, randomized, double-blind, phase IV study. Clin Ther. 2012; 34(11): 2202-2211.

24. Witek TJ Jr, Canestrari DA, Miller RD, et al. Characterization of daytime sleepiness and psychomotor performance following $\mathrm{H}_{1}$ receptor antagonists. Ann Allergy Asthma Immunol. 1995; 74(5): 419-426.

25. Ishibashi T, Horisawa T, Tokuda K, et al. Pharmacological profile of lurasidone, a novel antipsychotic agent with potent 5-HT7 and 5-HT1A receptor activity. J Pharmacol Exp Ther. 2010; 334(1): 171-181.

26. Leucht S, Cipriani A, Spineli L, et al. Comparative efficacy and tolerability of 15 antipsychotic drugs in schizophrenia: a multiple-treatments meta-analysis. Lancet. 2013; 382(9896): 951-962.

27. Horiguchi M, Huang M, Meltzer HY. The role of 5hydroxytryptamine 7 receptors in the phencyclidine-induced novel object recognition deficit in rats. J Pharmacol Exp Ther. 2011; 338(2): 605-614.

28. Guilleminault C, Brooks SN. Excessive daytime sleepiness: a challenge for the practising neurologist. Brain. 2001; 124(Pt 8): 1482-1491.

29. Rosenheck RA. Effectiveness versus efficacy of second-generation antipsychotics: haloperidol without anti-cholinergics as a comparator. Psychiatr Serv. 2005; 56(1): 85-92.

30. Leucht S, Corves C, Arbter D, et al. Second-generation versus firstgeneration antipsychotic drugs for schizophrenia: a meta-analysis. Lancet. 2009; 373(9657): 31-41. 